\title{
THE NATURAL HISTORY OF THE PARTIAL THORACIC STOMACH (HIATUS HERNIA) IN CHILDREN*
}

BY

\author{
I. J. CARRÉ \\ From the Department of Child Health, Queen's University, Belfast
}

(RECEIVED FOR PUBLICATION FEBRUARY 9, 1959)

'It appears to me a most excellent thing for the physician to cultivate prognosis . . . he will manage the cure best who has foreseen what is to happen from the present state of matters.'

Notwithstanding the enormous medical achievements of the past half century this Hippocratic counsel remains today as fundamental a truth as when first propounded some 2,000 years ago. Regrettably, however, this aspect of medical knowledge is all too frequently ignored. There is no doubt that in the case of children with a partial thoracic stomach ('hiatus hernia', 'congenital short oesophagus') the divergent views expressed on prognosis and on the need for and value of particular forms of treatment emanate from a lack of a clear understanding of the natural history. The present review is aimed at remedying this deficiency and constitutes an attempt to outline the clinical progress of children affected with a partial thoracic stomach in the absence of either surgical or postural therapy.

\section{Definition of Abnormality and Terminology}

The following diagnostic criteria have been adopted. Only those children have been considered in whom a loculus of stomach could be demonstrated above the diaphragm either on radiological examination or at operation or necropsy. In all instances the protrusion of stomach has been through the oesophageal hiatus and the gastro-oesophageal junction has been situated within the chest at the upper aspect of the intrathoracic gastric loculus. The stomach has been the sole abdominal viscus demonstrated as protruding into the thorax (Fig. 1). Children with gastro-oesophageal incompetence but with no definite intrathoracic gastric loculus have not been considered.

The gastro-oesophageal abnormality, as defined,

* This paper is based on part of a thesis accepted for the degree of M.D., University of Cambridge.

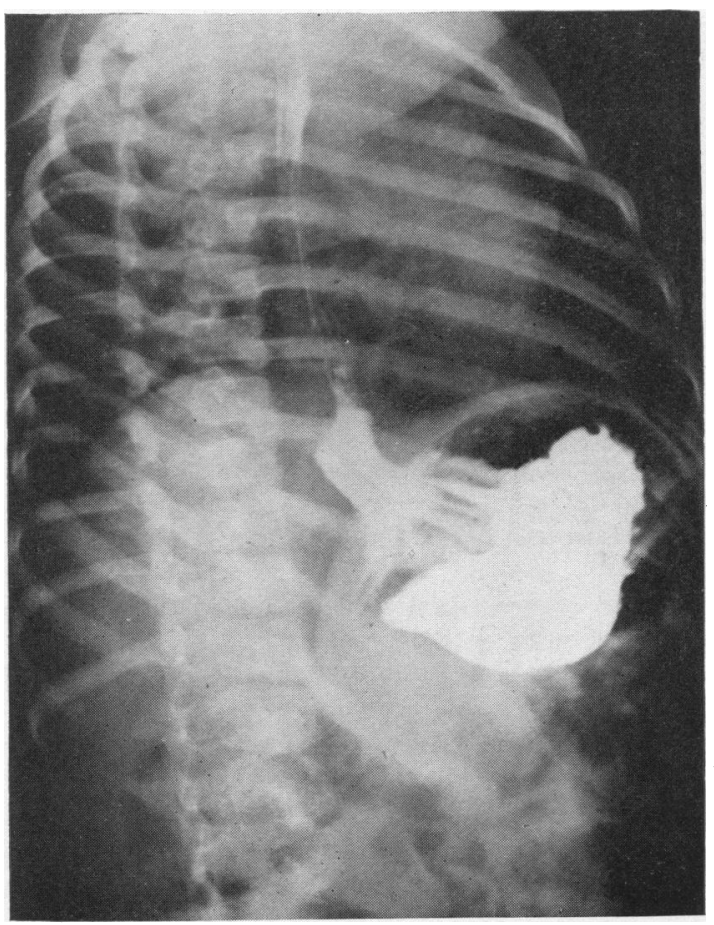

Fig. 1.-Example of a partial thoracic stomach in a 12-month-old child.

is referred to throughout as a 'partial thoracic stomach'. On the evidence available the use of a descriptive term has been preferred to one signifying a specific pathogenesis.

\section{Material}

The following review forms part of a study originally undertaken in 1951 at the Children's Hospital, Birmingham, and later continued at the Royal Children's Hospital, Melbourne, and the Royal Belfast Hospital for Sick Children. During 
this period, 235 children with a proven partial thoracic stomach have been seen.

At the outset it is necessary to emphasize two major difficulties encountered in effecting this survey. The almost universal use of either surgical or postural methods of treatment since 1951 has meant that of patients diagnosed during subsequent years few could be considered in this review which is aimed primarily at outlining the clinical progress in the absence of either form of therapy. It follows that assessment of the clinical progress has had to be based on evidence relating chiefly to patients who attended hospital before 1951. As a result, though recognized as undesirable, it has none the less been necessary in carrying out this review to rely largely on retrospective evidence. The measures adopted to obviate errors inherent in such a retrospective study will be outlined in the appropriate sections.

Before 1951, a partial thoracic stomach was infrequently recognized in children. References to fewer than 100 children with an abnormality corresponding to a partial thoracic stomach were found in the medical literature published before 1951 (Carré, 1957). Thus, a second major problem was to collect a sufficiently large number of untreated patients to permit of analysis and conclusions. It appeared logical to assume that the greater number of children recognized as having a partial thoracic stomach subsequent to 1951 represented not a true absolute increase in incidence but merely reflected improved diagnosis and a greater awareness of the condition. This being so, it was argued that provided the abnormality persisted, even despite cessation of symptoms, it should be possible to recognize such cases in retrospect. To test this hypothesis, a separate retrospective follow-up study was undertaken (Carré and Astley, in preparation). Selected patients who had attended the Children's Hospital, Birmingham, between 1930 and 1950 with either an oesophageal abnormality or vomiting of undetermined cause were clinically and radiologically reassessed. As a result, over $\mathbf{4 0}$ previously unrecognized examples of the condition were discovered. The discovery of these cases resolved the shortage of untreated patients available for consideration.

\section{Observations}

\section{Classification of Patients into Clinical Groups}

For convenience of presentation the clinical progress of untreated children affected with a partial thoracic stomach is considered for each of three types of case: A. Survivors (i) Patients with no oesophageal stricture. (ii) Patients with a partial thoracic stomach complicated by a stricture of the oesophagus. B. Deaths.
A. Survivors. (i) Patients with no Oesophageal Stricture. In assessing the clinical progress of children considered in this section it has been necessary, for reasons already stated, to rely largely on parental retrospective information. It is, therefore, pertinent to consider the precautions taken to obtain as reliable a clinical history as possible.

All patients reviewed in this section were seen personally and one or both parents interviewed. A thorough and unhurried evaluation of the clinical progress was made at the time of interview. To provide for uniformity of information a case history sheet was drawn up listing specific points for enquiry. Questions to which answers appeared doubtful were listed with the parents' replies, if any, attached. These were then given to the parents for reconsideration at home. This provided them with an opportunity to reconsider the child's early history and to consult with other members of the family. If, on subsequent reflection, they considered their replies to have been inaccurate they were asked to return the list with their amended answers, or alternatively, such inaccuracies were corrected at the time of a subsequent interview.

In every instance it has been possible to augment and check the clinical history with case notes kept at the time of the child's original hospital attendance during infancy or early childhood. Whenever possible, information has been additionally checked by reference to maternity, health visitor and welfare clinic records and in a few instances by enquiry from the family doctor.

To ensure as much impartiality as possible in assessing the severity of symptoms, the following objective method has been used. Symptoms have been classified into the following categories of severity:

(i) Frequent: If vomiting and/or difficulty in swallowing solid food was noted to occur daily or at least on alternate days in children taking a normal diet for age. The routine use of a mashed diet occasioned by a child's inability to swallow solids has been interpreted as implying the existence of frequent symptoms despite the fact that the child on its mashed diet might have been having little or no vomiting or dysphagia.

(ii) Moderate: If vomiting and/or difficulty in swallowing solid food was noted to occur on an average of less than three times weekly but at least monthly in a child taking a normal diet for age.

(iii) Minimal: If vomiting and/or difficulty in swallowing solid food were absent or occurred on average less than once a month in a child taking a normal diet for age. 
Selection of Patients. In addition to patients with an oesophageal stricture all children who had received either postural or surgical treatment previous to their last review have been excluded from this particular survey. Patients have also been excluded who had an associated unrelated chronic disorder which could have conceivably influenced their clinical progress.

Only children aged 4 years or more at the time of their last review have been considered. This age limit has been arbitrarily adopted so as to allow for as long a follow-up as possible while concurrently providing a sufficiently large group of patients to permit of conclusions.

Patients whose gastro-oesophageal abnormality was first diagnosed during life before three months of age have not been included. The progress of these infants has been considered separately in a 'prospective' review.

There were 53 patients available for study. At 4 years of age 26 had 'minimal' symptoms, 18 had improved but still suffered from 'moderate' symptoms while nine were vomiting daily or on alternate days. Further study of the symptomatic progress made by these children suggested that the clinical response to weaning on to solid food might serve as a useful prognostic guide. Of the 26 who were relatively free of symptoms at 4 years of age, 19 had shown improvement either before or at the time of weaning on to solids: of the 27 with 'frequent' or 'moderate' symptoms at 4 years, only two had improved with the introduction of mixed feeding (Table 1). On this basis, these children

TABLE 1

CLINICAL PROGRESS OF 53 UNTREATED PATIENTS RELATED TO THE SYMPTOMATIC EFFECT OF WEANING ON TO SOLID FOOD

\begin{tabular}{|c|c|c|c|}
\hline \multirow[b]{2}{*}{$\begin{array}{c}\text { Classification of } \\
\text { Symptoms at } 4 \text { Years }\end{array}$} & \multirow[b]{2}{*}{$\begin{array}{c}\text { Number of } \\
\text { Patients }\end{array}$} & \multicolumn{2}{|c|}{$\begin{array}{l}\text { Clinical Condition on } \\
\text { Weaning }\end{array}$} \\
\hline & & Improved & $\begin{array}{l}\text { No change } \\
\text { or worse }\end{array}$ \\
\hline $\begin{array}{l}\text { Minimal } \\
\text { Moderate } \\
\text { Frequent }\end{array}$ & $\begin{array}{r}26 \\
18 \\
9\end{array}$ & $\begin{array}{r}19 \\
2 \\
0\end{array}$ & $\begin{array}{r}7 \\
16 \\
9\end{array}$ \\
\hline
\end{tabular}

have been re-classified into two groups: Group I: Patients whose vomiting had improved either before or coincident with weaning on to solids. Group II: Patients whose symptoms either commenced, persisted unchanged or increased with the introduction of mixed feeding.

The progress of patients in each group is illustrated in Figs. 2 and 3. The different clinical course followed by the majority of children in each group is evident. In Group I, only five of 21 children continued to have 'moderate' or 'frequent' symptoms after the age of 2 years and only two were not either completely or relatively free of symptoms by 4 years of age. By contrast, 30 of 32 children in Group II had 'moderate' or 'frequent' symptoms persisting after 2 years of age and 25 of these were still classified as having symptoms of at least 'moderate' severity when 4 years old. Moreover, a number of the older children in this latter group did not enjoy relative freedom of symptoms until many years later; of 15 aged 7 years or more when last reviewed, three had had symptoms of 'moderate' and four of 'frequent' severity up to 7 years.

A. Survivors. (ii) Patients with an Associated Oesophageal Stricture. The aim of this section of the review is to establish a clinical relationship between patients with an oesophageal stricture and those discussed in the previous section who were free of this complication. Clinical progress subsequent to the recognition of a stricture is not considered.

Thirty-six patients have been seen with both a partial thoracic stomach and an oesophageal stricture. In only one child was the onset of symptoms delayed until after 12 months of age. This patient had had no symptoms until the age

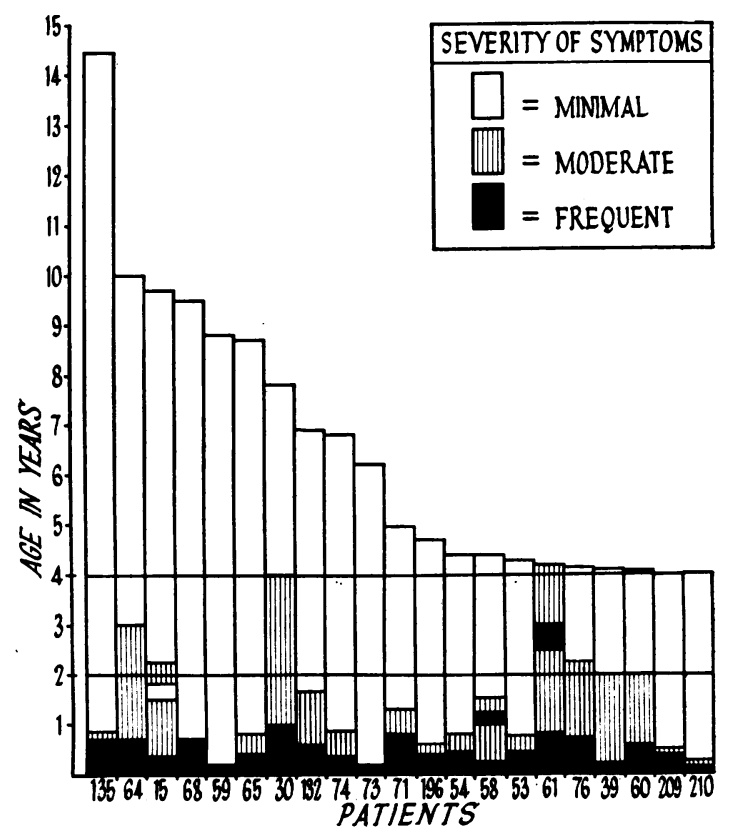

FIG. 2.-Clinical progress of 21 untreated Group $I$ patients. Each column represents the clinical progress of a single patient. 


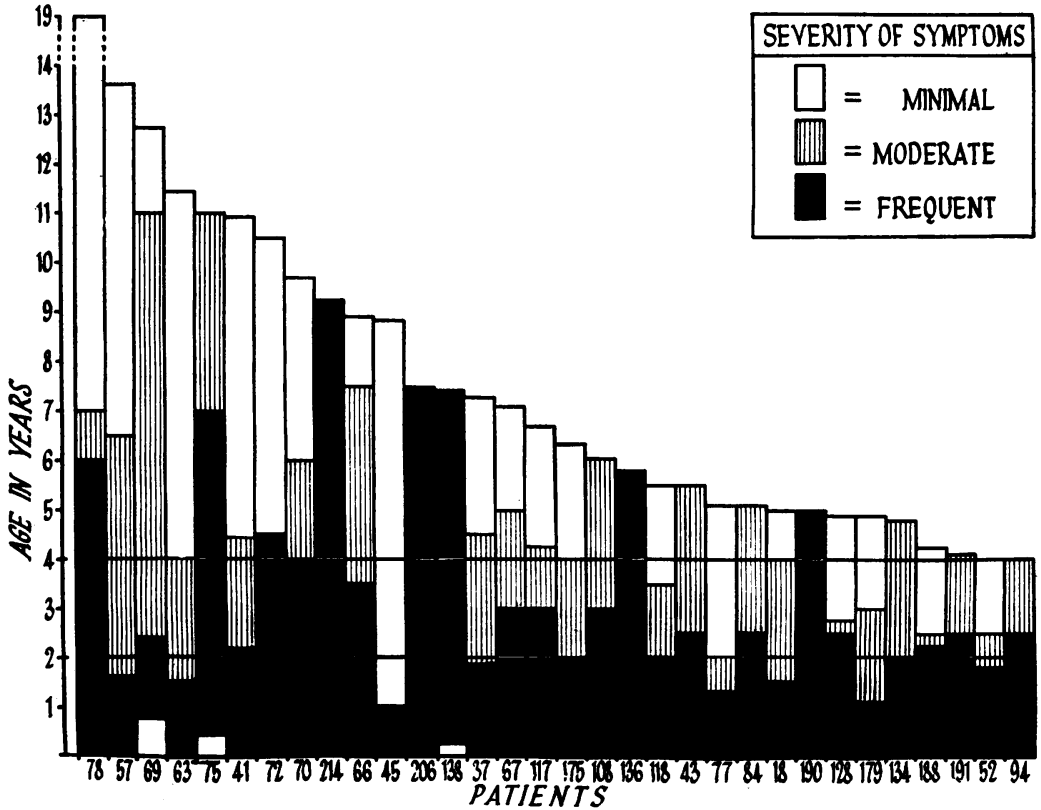

Fig. 3.-Clinical progress of 32 untreated Group II patients. Each column represents the clinical progress of a single patient.

of 5 years and 9 months. At this time she became critically ill with meningococcal septicaemia. During her illness she vomited repeatedly and this continued following her recovery. Radiological examination and oesophagoscopy confirmed the presence of an oesophageal stricture. The recognition of a partial thoracic stomach was made on review when she was aged 16 years and 4 months. Whether the partial thoracic stomach was present previous to her illness or developed subsequently as a result of cicatricial changes is conjectural.

It was not possible to determine accurately the age at which symptoms commenced in two. other children. Of the remaining 33 patients, 30 had commenced vomiting within the first 4 weeks of life; the onset of symptoms in three patients had coincided with attempts to wean on to solid food.

In four instances the clinical response to weaning was uncertain. Of the remaining 31 patients whose symptoms had commenced in infancy, one child only was stated to have improved with weaning. Symptoms were recorded in three patients as starting with weaning, in eight as showing no improvement and in 19 as being definitely aggravated when weaning on to a solid diet was attempted. Nothing in the early clinical progress of these latter 30 patients distinguished them from the Group II children discussed in the previous section.
B. Deaths. In order to complete the assessment of the natural history a brief account is presented of the available data relating to the cause of death in children with a partial thoracic stomach.

The case records of 13 children who died with a proven partial thoracic stomach were available for study. None of these children had been treated by sustained posture; four had had surgical treatment. A necropsy was performed on 12 of these patients; the radiologically diagnosed partial thoracic stomach in the remaining child was confirmed at operation.

One child died of miliary tuberculosis when $3 \frac{1}{2}$ months old; the partial thoracic stomach was an incidental necropsy finding. The cause of death in two patients was unrelated to their gastro-oesophageal abnormality. The cause of death in a fourth child could not be accurately determined as a full autopsy report was not available.

Four children died following operative procedures. Three died within 48 hours of operation. In one, aged 3 weeks, a repair of a 'hiatus hernia' had been performed; two others, aged 2 years 3 months and 2 years 10 months, had had an oesophageal stricture resected and an oesophago-gastrostomy performed. The fourth patient was 13 years old. He died 23 days after having had an oesophageal stricture resected and an oesophago-jejunostomy performed. Death was due to a generalized peritonitis following on a break down of the anastomosis.

The fatal outcome in three children was attributed to inanition secondary to intractable vomiting. It is probable that biochemical disturbances contributed to the death of these infants. Unfortunately, biochemical data were not available. These infants were 10 weeks, 11 weeks and $4 \frac{1}{2}$ months old at the time of their death. One infant died when 5 months old from bronchopneumonia; additional contributory factors were prematurity, persistent vomiting from birth and marasmus. The remaining child died when 2 years 2 months old from bronchopneumonia and pneumococcal peritonitis. A gastrostomy had been performed four months previously. None of 
these latter five children had an oesophageal stricture.

The evidence though scanty suggests that in the absence of a complicating oesophageal stricture death in non-surgically treated patients is likely to occur during infancy from a combination of inanition, biochemical disturbances and infection.

Clinical Groups. On the basis of the evidence presented it is possible to define the following relatively distinct clinical groups: natural history cannot be obtained by merely comparing the number of patients corresponding with any one group with the total number available for study. This is mainly due to the fact that many of the patients were recognized following a clinical and radiological re-assessment of previously undiagnosed patients. These patients, who first attended hospital between 1930-50, were selected for review on evidence which suggested that they might have a partial thoracic stomach. Features which prompted selection were continued unexplained vomiting in

\begin{tabular}{|c|c|c|c|}
\hline Group & Change in Symptomatology & Veaning & Prognosis \\
\hline $\begin{array}{lr}\text { Survivors } & \text { I } \\
& \text { II }\end{array}$ & $\begin{array}{l}\text { No symptoms or improved } \\
\text { No improvement or worse }\end{array}$ & $\begin{array}{ll}\cdots & \cdots \\
\cdots & \cdots\end{array}$ & $\begin{array}{l}\text { Benign course. Majority free of symptoms by } 2 \text { years. } \\
\text { (a) Prolonged clinical course with 'moderate' or 'frequent' vomiting and/or } \\
\text { dysphagia commonly persisting to at least } 4 \text { years of age. No oesophageal } \\
\text { stricture. } \\
\text { (b) Symptomatology and progress dependent on presence of an oesophageal } \\
\text { stricture. }\end{array}$ \\
\hline Deaths & & & $\begin{array}{l}\text { In the absence of an oesophageal stricture death likely to occur in early infancy } \\
\text { from a combination of inanition, biochemical disturbances and infection. }\end{array}$ \\
\hline
\end{tabular}

\section{Incidence of Clinical Groups}

What percentage of all untreated clinically affected patients progress in a manner corresponding with each of the clinical groups outlined? A survey aimed at answering this question was undertaken at the Children's Hospital, Birmingham, during 1951-3. The following review is based on the results of that survey. Only information relating to patients attending the Children's Hospital, Birmingham, is therefore considered in this section.

In analysing the available data some degree of case selection has been necessary. Uncommon or difficult clinical problems tend to be referred to the Children's Hospital, Birmingham, from areas far removed from those routinely served by the hospital. As a result, in any paediatric problem an unduly large number of difficult and complicated cases are seen. For example, of patients with a partial thoracic stomach complicated by an oesophageal stricture, 16 of $25(64 \%)$ came from homes outside the Birmingham City boundary. The comparable figures for patients with an uncomplicated partial thoracic stomach were 52 of $143(36.4 \%)$. To obviate discrepancies which would arise from such irregular regional distribution, only patients living within the city have been considered.

Secondly, as the object of this survey is to evaluate the natural history in the absence of either surgical or postural treatment it has been necessary to rely almost exclusively on information relating to patients who attended hospital before 1951 .

Despite this case selection, a true picture of the early childhood and the presence of an oesophageal stricture, thereby automatically providing for preferential selection of severely affected children, i.e. Group II ( $a$ ) and (b).

For this reason an alternative and more complex method of determining the relative incidence of each clinical group has had to be used. This has been done by estimating the number of children of each clinical group who could be expected to attend the Children's Hospital, Birmingham, within a period of four years. For convenience, these groups are considered in the reverse order to the previous section.

Deaths. Five children with a partial thoracic stomach were known to have died during the 10 years, $.1940-50$ inclusive. It is universally acknowledged that minor protrusions of the stomach through the oesophageal hiatus may be readily overlooked unless careful attention is paid to that area during the post-mortem examination. On the assumption that children with a partial thoracic stomach dying secondarily to the adverse effects of vomiting are likely to show autopsy evidence of oesophagitis, it would be expected that the pathological changes in the lower oesophagus would prompt a careful examination of that region. It is arguable that despite a typical clinical history and pathological changes in the lower oesophagus a minor degree of a partial thoracic stomach could still remain unrecognized. However, no record was found following a search of the autopsy records, for the four-year period 1947-50 
inclusive, of a child with clinical features during life compatible with those of a partial thoracic stomach and who on necropsy had oesophagitis and ulceration of the lower oesophagus without a specifically mentioned intrathoracic cardia. During this same four-year period a minor degree of partial thoracic stomach was recorded as an incidental finding in one infant. Such an observation had not been made previously.

The probable authenticity of post-mortem evidence suggesting that death occurs infrequently in children with a partial thoracic stomach uncomplicated by an oesophageal stricture is supported by hospital records for the period during which this particular survey was in progress, i.e. 1951-3. No child with a partial thoracic stomach treated conservatively died during this period. Despite a careful routine examination of the oesophageal hiatus at autopsy no example of a partial thoracic stomach was detected during these years. I am grateful to Dr. H. S. Baar for this latter observation.

For these reasons it is considered that the postmortem records for the four years 1947-50 inclusive reflect a reasonably reliable estimate of the number of untreated children dying as a result of clinical disturbances occurring in association with a partial thoracic stomach uncomplicated by an oesophageal stricture. During this time, two infants died from the effects of intractable vomiting; neither had been treated by posture or surgery. As almost half the total number of patients attending the Children's Hospital come from homes outside the city the mortality rate among infants of Birmingham residents may thus be approximately computed as one in four years.

Survivors. Group II (b). Patients with an Associated Stricture of the Oesophagus. During the 10 years, 1940-50, 14 children attending hospital were diagnosed as having a stricture of the lower oesophagus. Thirteen of these were traced and clinically reviewed. All were found to have an associated partial thoracic stomach on fluoroscopy. The untraced child lived outside the city boundary and the failure to review this patient is therefore immaterial to the present assessment. Only four of these children came from homes within the city, an incidence of one or two new cases every four years. By reason of the persistent and unpleasant symptoms associated with oesophageal obstruction it is certain that few, if any, children with an oesophageal stricture would fail to attend hospital. It is also extremely unlikely that an oesophageal stricture would remain undiagnosed. These results have therefore been accepted as providing a true indication of the occurrence of an oesophageal stricture among untreated children with a partial thoracic stomach living within the city of Birmingham.

Survivors. Group II (a). Patients with no Oesophageal Stricture but with Symptoms Commonly Persisting to 4 years of Age and Later. In an endeavour to obtain a reliable estimate of the incidence of this type of child, children who attended hospital during the four years 1947-50 inclusive, with unexplained vomiting persisting over the age of 6 months, were both clinically and radiologically reviewed. These years were chosen for the following reasons:

Patients would be at least 3 years old at the time of review. It was considered that this provided a reasonably long follow-up period for assessing the clinical progress, particularly with regard to the development of an oesophageal stricture.

An accurate list of all children with vomiting persisting over the age of 6 months was available for these years. This list was partly compiled from information kindly supplied by Dr. B. S. B. Wood.

Very few of the patients attending hospital during this period would have been treated by either posture or surgery.

As a result of this review it can be stated that of all patients attending hospital for the first time during 1947-50 and who were shown either then or later to have a partial thoracic stomach, 17 are known to have progressed in a manner comparable to that of Group II (a) patients; 11 lived within the City of Birmingham.

Survivors. Group I Patients Mostly Free of Symptoms by 2 Years of Age. The majority of children corresponding to this group show considerable symptomatic improvement during infancy. As a result, few are likely to attend hospital after the age of 12 months. It follows that unless diagnosed during infancy these particular children are likely to remain unrecognized.

In view of the greatly increased numbers diagnosed during infancy since 1951 it is certain that records before this date are unreliable with respect to this type of child. Since 1951, almost all infants have been treated by posture and are not therefore suitable for analysis. However, the years since 1951 provide an indication of the total hospital attendance of all groups. During the two and a half years period covered by this particular study, 41 infants under 12 months of age were diagnosed as having a partial thoracic stomach; 24 came from homes within the city. As these infants represent only those with 
sufficiently worrying symptoms to necessitate their attendance at hospital, these figures must be regarded as a conservative estimate of the true incidence.

It may thus be concluded that within a period of four years at least 38 infants from homes within the city will be brought to the Children's Hospital, Birmingham, because of symptoms associated with a partial thoracic stomach. Evidence has been presented indicating that of these patients one would probably die in infancy, two would have an associated oesophageal stricture (Group II (b)) and 11 others would suffer from vomiting or dysphagia for many years (Group II $(a)$ ) in the absence of postural or surgical treatment. It may be inferred, therefore, that 24 infants with a partial thoracic stomach attending hospital during a similar period would make an early spontaneous symptomatic recovery.

It is now possible to complete the assessment of he natural history by including the approximate proportion of all affected infants likely to correspond with each of the previously defined clinical groups. affected children progress in an identical manner during the early weeks of life irrespective of the eventual clinical outcome. No bias, therefore, should exist in favour of a particular clinical group in a series consisting of patients first diagnosed before 3 months of age. It is obvious that this would not apply to a series which included, for example, children originally diagnosed as having a partial thoracic stomach when between 12 and 18 months of age. For these latter children would represent mostly patients with persistent symptoms, i.e. Group II cases, as the mildly affected Group I type of child would be at this age either symptomfree or considerably improved and therefore unlikely to be brought to hospital for investigation. For this reason the recognition of a partial thoracic stomach during life before the age of 3 months has been adopted as an essential condition for consideration of patients in this analysis. As with the retrospective analysis, so allowance has had to be made for possible influences resulting from thera-

\begin{tabular}{|c|c|c|c|}
\hline Group & $\begin{array}{c}\text { Change in Symptomatology on } \\
\text { Weaning to Solid Food }\end{array}$ & Prognosis & $\begin{array}{l}\text { Approx. } \% \text { of all } \\
\text { Clinically } \\
\text { Affected Patients }\end{array}$ \\
\hline $\begin{array}{lr}\text { Survivors } & \text { I } \\
& \text { II }\end{array}$ & $\begin{array}{l}\text { No symptoms or impioved } \\
\text { No improvement or worse }\end{array}$ & $\begin{array}{l}\text { Benign course. Majority free of symptoms by } 2 \text { years } \\
\text { (a) Prolonged clinical course with moderate or frequent vomiting } \\
\text { and/or dysphagia commonly persisting to at least } 4 \text { years of } \\
\text { age. No oesophageal stricture. } \\
\text { (b) Symptomatology and progress dependent on presence of an } \\
\text { oesophageal stricture. }\end{array}$ & $\begin{array}{c}\text { 60-65 } \\
30 \\
5\end{array}$ \\
\hline Deaths & & $\begin{array}{l}\text { No oesophageal stricture. Death likely to occur in infancy from } \\
\text { combination of marasmus, biochemical disturbances and infection. }\end{array}$ & $<5$ \\
\hline
\end{tabular}

\section{'Prospective' Survey of Natural History}

For reasons stated the preceding assessment of the natural history has, of necessity, been based largely on retrospective information. The following 'prospective' survey has been undertaken in an attempt to obtain confirmation of these deductions.

Evidence has been presented elsewhere (Carré, 1957) showing that with few exceptions clinically peutic procedures; children given postural treatment or who were operated on before the age of 12 months have been excluded.

Only nine of the 235 patients who have been seen qualify for consideration. The clinical progress of these children has been objectively assessed using the classification of symptoms previously described (Table 2). It will be seen that in five children

TABLE 2

PROGRESS OF NINE UNTREATED PATIENTS DIAGNOSED BEFORE 3 MONTHS OF AGE

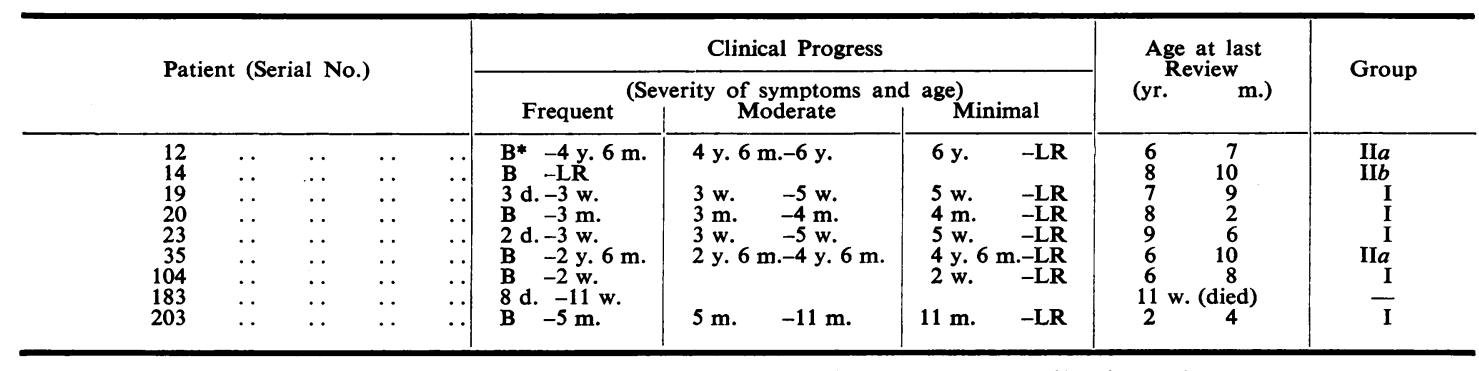

* Abbreviations: $\quad B=$ birth, $\quad d=$ days, $\quad w=$ weeks $\quad m=$ months, $\quad y=$ years, $\quad$ LR=last review. 
symptoms improved spontaneously either before or coincident with weaning on to solid food (Group I patients). This improvement was subsequently maintained and from 12 months of age all five patients had remained free of troublesome symptoms up to their last review; four of these children were over $6 \frac{1}{2}$ years old. On the other hand, the three children whose vomiting had not improved with weaning (Group II patients) suffered from troublesome symptoms beyond 4 years of age. One (Case 35) had symptoms of 'moderate' severity until about $4 \frac{1}{2}$ years. Another (Case 12) had symptoms of similar severity until 6 years of age; this latter child when 17 months old had had a surgical repair of the 'hiatus hernia'. The third child (Case 14) developed an oesophageal stricture when about $2 \frac{1}{2}$ years old. The remaining patient (Case 183) died when 11 weeks old.

Allowing for the few patients studied these observations conform with the natural history deduced from the retrospective analysis. They also confirm that changes in symptomatology on weaning to solid food afford a useful guide to the patient's future progress.

\section{Discussion}

References to only 93 children with a gastrooesophageal abnormality conforming to that of a partial thoracic stomach have been found in the literature published before 1951; only three publications referred to more than five patients (Carré, 1957). The frequently reported association of a partial thoracic stomach and an oesophageal stricture among these patients is striking. In the three series published by Findlay and Kelly (1931), Olsen and Harrington (1948) and Allison (1948), 21 of the 22 children mentioned had a stricture of the oesophagus. Of the remaining 71 children reported, 17 had an associated oesophageal stricture; in 24 insufficient information was provided for an accurate assessment to be made. Therefore, 38 of the 69 children, of whom sufficient information was available, were listed as having an associated oesophageal stricture. Judged by the high recorded incidence of concomitant oesophageal strictures the prognosis of children with a partial thoracic stomach appeared grave. At variance with this view were the conclusions of Lelong, Aimé, Aubin and Bernard (1939), Lelong, Lamy and Aimé (1940), Lelong, Aimé and Aubin (1941), Schmit (1940) and Bertoye, Bernheim and Moron (1946) who maintained that the disorder commonly underwent spontaneous cure. Supporting evidence was provided by isolated observations recorded by Christiansen (1941), Nadaud (1942), Kohler and Papillon (1946) and Nicod (1948). Each of these authors reported a single patient who had become symptom-free by 12 months of age. None of these children had an oesophageal stricture.

Despite the publication since 1951 of observations on larger series of affected children no clear picture of the natural history has evolved and similar differing opinions continue to be expressed. Belsey (1954) and Forshall (1955), for example, both regard the development of complications as constituting a major problem, while Carré (1952), Fox and Hunter (1954) and Swyer (1955) view the future of children with a partial thoracic stomach with comparative optimism. The knowledge of the natural history gained from this study provides both an explanation for such differing opinions and a rational basis for reviewing published information.

Excluding reports based on children considered in the present study (Carré, Astley and Smellie, 1952; Astley and Carré, 1954; Carré, 1957) all but one of the larger series published since 1951 have emanated from surgical clinics (Roviralta, 1952; Duhamel, Sauvegrain and Masse, 1953; Belsey, 1954; Waterston, 1954; Forshall, 1955). This raises two main considerations when interpreting these authors' observations. Firstly, many patients were treated surgically; the progress of such patients cannot be regarded therefore as indicating the natural outcome of the disorder. Secondly, because of the tendency for more severely affected patients to gravitate to surgical departments series published from these units will inevitably include a disproportionately large number of patients with complications. It is probable that most of the patients reported by these workers were of a type similar to those classified in this study as showing no improvement with weaning on to a solid diet (Group II). Such patients would be likely either to develop an oesophageal stricture or to suffer from persistent troublesome symptoms for many years. Unfortunately, the published information is inadequate for this contention to be conclusively substantiated but confirmatory support is provided by the number of reported patients who had an associated stricture of the oeosophagus: namely, five of 24 (Roviralta, 1952), nine of 49 (Duhamel et al., 1953), 20 of 50 (Belsey, 1954), 20 of 132 (Waterston, 1954) and eight of 39 (Forshall, 1955). Addition of these figures shows that 62 of 294 children with a gastro-oesophageal abnormality corresponding to a partial thoracic stomach had an oesophageal stricture as well, an incidence of slightly over one in five. This compares closely with the frequency of one in six among Group II patients computed from this study. The somewhat higher incidence of oesophageal strictures among patients 
in the published series is probably due to the fact that whereas very few patients, if any, with an oesophageal stricture would fail to be referred for surgical treatment only a proportion of those without this complication would be likely to attend surgical departments. Moreover, as illustrated by the present study, patients with an associated stricture of the oesophagus are likely to include many referred from outlying areas not usually served by that hospital.

Before 1951, a partial thoracic stomach was uncommonly recognized in the absence of complications and hence any series which includes patients diagnosed before this date must inevitably include an excessively large number of severely affected patients. This fact is illustrated by Thomsen's (1955) publication, the only large series reported in addition to those considered. This author's series consists of 53 patients whose first hospital attendance was during the previous 30 years; of 28 who attended hospital before 1950, 14 had an associated stricture of the oesophagus, while of 25 who attended after that date only four had this complication. An interpretation of the prognosis based on an analysis of such a series without regard to this fact would obviously provide a completely misleading conclusion.

It is evident that the foregoing publications relate to selected material including a preponderance of severely affected patients. It can be appreciated how an uncritical evaluation of these reports could lead to a totally unrealistic and pessimistic attitude were such observations to be applied to all children affected with a partial thoracic stomach.

Symptoms attributable to a partial thoracic stomach commence within the first six weeks of life in over $90 \%$ of all clinically affected patients (Carré, 1957). As demonstrated in this study, symptoms in about two of every three of these children can be expected, in the absence of either postural or surgical treatment, to improve spontaneously during infancy. These observations afford an explanation for the more optimistic views on prognosis expressed by Roviralta (1952), Fox and Hunter (1954), Swyer (1955) and Plarre (1956) as these investigators have for the most part based their conclusions on a prospective review of patients diagnosed during early infancy. Moreover, the patients reported were, with few exceptions, treated by posture, a therapeutically beneficial procedure when instituted in early infancy (Carré, 1957). These authors' observations, therefore, do not truly reflect the natural history of the disorder but rather the outcome to be expected from treating infant patients by posture.
In 1953 Kelly published the results of a review of six of the nine patients previously reported by Findlay and Kelly in 1931. All had originally both a partial thoracic stomach and an oesophageal stricture. On review, these patients were between 23 and 30 years of age. All six were stated to be leading 'a normal active life' though not one was entirely free of symptoms.

Twenty-six of the patients reported by Thomsen (1955) were 5 years old or more at the time of their last review. Twenty-three suffered from troublesome symptoms beyond 4 years of age; 13 had an oesophageal stricture.

The literature contains reports of 19 other patients who had received neither postural nor surgical treatment other than dilatations for an oesophageal stricture during the first five years of life (LeWald, 1924; Wright, 1933; Christiansen, 1941; Nadaud, 1942; Huizinga, 1947; Schondel, 1947; Putney, 1948; Barrett, 1950; Pettersson, 1951; Nelson, 1953; Robb, 1954; Franklin and Henderson, 1955; Plarre, 1956). Two patients only were free of symptoms when last seen (Nadaud, 1942; Robb, 1954); 12 had an associated stricture of the oesophagus.

Thus, all reported long term retrospective reviews refer to patients with either an associated oesophageal stricture or symptoms persisting beyond 4 or 5 years of age. It is important that such reviews should be viewed in their correct perspective for although informative with regard to the progress of severely affected patients it is obvious that they do not in themselves provide a representative picture of the natural history.

It is apparent therefore that the published information does not provide a balanced and impartial picture of the natural history. However, it should theoretically be possible to obtain an indication of the overall prognosis by affecting a 'prospective' review of published cases similar to that described in this study. Reasons have been given for confining such a review to patients whose gastro-oesophageal abnormality was recognized during life and in early infancy. For only six of the reported patients given neither postural nor surgical treatment during the first $\mathbf{1 2}$ months of life can it be certain that the diagnosis was established in early infancy. Kohler and Papillon (1946) reported a child diagnosed at 12 days who was symptom-free when last seen at 12 months of age. Nicod (1948) and Humeau (1954) each reported a similar patient diagnosed at 3 months and 5 weeks and followed-up to 10 months and $15 \frac{1}{2}$ months respectively. The latter author also referred to an infant recognized as having a partial thoracic stomach at 2 weeks of age who died at 19 days from 
bronchopneumonia. One child reported by Robb (1954) was diagnosed at 4 months. This patient developed an oesophageal stricture. This worker also recorded a child diagnosed at 5 months of age as having an 'hiatus hernia'. This patient improved spontaneously, became symptom-free and had remained so to the time of her last review at 10 years. Thus, of these six reported patients, four made an uninterrupted symptomatic recovery, one developed a stricture of the oesophagus and one died. These observations are comparable to those recorded in this study.

In 1952 it was suggested that the clinical response to weaning to solid food might serve as a useful guide to the patient's future progress (Carré, 1952). The more extended observations recorded in this study have confirmed this view.

\section{Summary}

A review is described from which has been determined the natural history of the partial thoracic stomach in children. Evidence is also presented indicating that changes in symptomatology on weaning to solid food provide a useful guide to a patient's future progress.

It is concluded that about $60-65 \%$ of all clinically affected and untreated children pursue a relatively benign clinical course, the majority being free of symptoms by 2 years of age. With but few exceptions, these children show improvement either before or coincident with weaning on to solid food. Symptoms in a further $35 \%$ are not improved by weaning on to a mixed diet. Most of these patients suffer from troublesome symptoms up to 4 years of age and longer. A few of these latter children, representing about $5 \%$ of all patients, develop an oesophageal stricture. It has been estimated that in the absence of an oesophageal stricture less than $5 \%$ of all untreated patients would die.

It is suggested that neglect of the study of the natural history has been largely responsible for the differing views expressed on prognosis and on the need for and value of particular forms of treatment. By critically evaluating published information in relation to the knowledge gained from this study it has been possible to explain how the divergent opinions expressed have come to be formulated.

I am considerably indebted to Dr. R. Astley of the Radiology Department, Children's Hospital, Birmingham, not only for many'radiological observations during the early part of this study but also for much valuable advice and ever-willing co-operation. I wish in addition to record my appreciation and gratitude to the following: Professor J. M. Smellie of the University of Birmingham to whom I am especially grateful for much support and encouragement; all members of the medical and surgical consultant staff of the Children's Hospital, Birmingham, the Royal Children's Hospital, Melbourne, and the Royal Belfast Hospital for Sick Children who have permitted me to examine and follow-up their patients; Dr. F. Plarre for the fluoroscopic examination of patients attending the Royal Children's Hospital, Melbourne, Dr. D. Boyd of the Royal Belfast Hospital for Sick Children for permission to undertake the fluoroscopic examination of patients in his department, and Dr. H. S. Baar of the Children's Hospital, Birmingharn, for access to autopsy records.

\section{REFERENCES}

Allison, P. R. (1948). Thorax, 3, 20.

Astley, R. and Carré, I. J. (1954). Radiology, 62, 351.

Barrett, N. R. (1950). Brit. J. Surg., 38, 175.

Belsey, R. (1954). Ann. roy. coll. Surg. Engl., 14, 303.

Bertoye, P., Bernheim, M. and Moron, M. (1946). Arch. franc. Pédiat., 3, 485.

Carré, I. J. (1952). Arch. Dis. Childh., 27, 300. (1957). M.D. Thesis. Cambridge.

Astley, $\mathbf{R}$ and Smellie, J. M. (1952)

Christiansen, H. (1941). Acta radiol. (Stockh.), 22, 360.

Duhamel, B., Sauvegrain, J. and Masse, N. P. (1953). Poumon, 9, 33. Findlay, L. and Kelly, A. Brown (1931). J. Laryng., 46, 797.

Forshall, I. (1955). Arch. Dis. Childh., 30, 46.

Fox, E. G. and Hunter, J. L. P. (1954). J. Irish med. Ass., 34, 136.

Franklin, R. H. and Henderson, I. D. (1955). Arch. Dis. Childh. 30, 55.

Huizinga, E. (1947). Ned. T. Geneesk., 91, 1132.

Humeau, A. (1954). M.D. Thesis. Univ. Bordeaux.

Kelly, H. D. Brown (1953). Proc, roy. Soc. Med., 46, 943.

Kohler, C. and Papillon, J. (1946). Arch. franc. Pédiat., 3, 485.

Lelong, M., Aimé, P. Aubin A. and Bernard, J. (1939). Bull. Soc. méd. Hôp. Paris, 55, 145 .

Aimé, P. and Aubin, A. (1941). Presse méd., 49, 106.

Lamy, M. and Aimé, P. (1940). Bull. Soc. méd. Hôp. Paris, 56, 681.

LeWald, L. T. (1924). Radiology, 3, 91.

Nadaud, P. (1942). J. Radiol. Electrol., 25, 139.

Nelson'T. Y (1953). Aust. N.Z J. Surg , 22, 192.

Nicod, M. (1948). Praxis, 37, 745 .

Nicod, M. (1948). Praxis, 37, 745. (1948). J. thorac. Surg., 17, 189

Olsen, A. M. and Harrington, S. W. (1948). J. thorac. Surg., 17, 189.

Plarre, F. E. (1956). Med. J. Aust., 2, 241.

Putney, F. J. (1948). Ann. intern. Med., 28, 1094

Robb, D. (1954). Aust. N.Z. J. Surg., 24, 18.

Roviralta, E. (1952). Les Vomissements du Nourrisson. Flammarion, Paris.

Schmit, L. (1940). M.D. Thesis. Paris

Schondel, A. (1947). Nord. Med., 33, 419.

Swyer, P. R. (1955). A.M.A. Amer.J. Dis. Child., 90, 421

Thomsen, G. (1955). Acta radiol. (Stockh.), Suppl. 129:

Waterston, D. (1954). Proc. roy. Soc. Med., 47, 536.

Wooler, G. H. (1948). Thorax, 3, 53.

Wright, A. J. (1933). J. Laryng., 48, 773. 